\title{
Transmission of methicillin-resistant Staphylococcus aureus strains between different kinds of pig farms
}

\author{
E. van Duijkeren ${ }^{\mathrm{a}, *}$, R. Ikawaty ${ }^{\mathrm{b}}$, M.J. Broekhuizen-Stins ${ }^{\mathrm{a}}$, \\ M.D. Jansen ${ }^{b}$, E.C. Spalburg ${ }^{\text {c }}$, A.J. de Neeling ${ }^{\text {c }}$, J.G. Allaart ${ }^{\mathrm{d}}$, \\ A. van Nes ${ }^{\mathrm{d}}$, J.A. Wagenaar ${ }^{\mathrm{a}}$, A.C. Fluit ${ }^{\mathrm{b}}$ \\ ${ }^{\text {a }}$ Department of Infectious Diseases and Immunology, Faculty of Veterinary Medicine, PO Box 80165, \\ Utrecht University, 3508 TD Utrecht, The Netherlands \\ ${ }^{\mathrm{b}}$ Department of Medical Microbiology, University Medical Center Utrecht, The Netherlands \\ ${ }^{\mathrm{c}}$ National Institute for Public Health and the Environment (RIVM), Laboratory for Infectious \\ Diseases and Perinatal Screening, Bilthoven, The Netherlands \\ ${ }^{\mathrm{d}}$ Department of Farm Animal Health, Faculty of Veterinary Medicine, Utrecht University, The Netherlands
}

Received 13 June 2007; received in revised form 18 July 2007; accepted 20 July 2007

\begin{abstract}
The main objective of the present study was to investigate if different kinds of pig farms, like farrowing farms and rearing farms, play a role in the transmission of methicillin-resistant Staphylococcus aureus (MRSA) to Dutch finishing farms. Twelve farrowing farms, 11 finishing farms, 6 farrow-to finish farms, 1 rearing farm and 1 centre for artificial insemination were included. Screening of 310 pigs from these 31 farms showed 35 pigs (11\%) to carry MRSA in their nares. On 7 of the $31(23 \%)$ investigated farms colonized pigs were found, including 3 finishing farms, 3 farrowing farms and 1 farrow-to-finish farm. The use of standard antimicrobial medication of the pigs seemed to be a risk factor for MRSA carriage. Screening of the pigs on six farms supplying pigs for the MRSA positive farms revealed that the pigs on all but one farm were MRSA positive. Genotyping revealed that all MRSA strains were non-typeable by PFGE using the SmaI restriction enzyme and had multilocus sequence type (MLST) ST398. Different spa-types were found including t011, t108, t567, t899 and t1939, but the spa-types on epidemiologically related farms were identical indicating that MRSA are transmitted between farms through the purchase of colonized pigs. Two SCCmec types were found among the MRSA: type IV and type V. SCCmec type V was predominant. On two farms MRSA isolates with ST398, the same spa-type but with different SCCmec types (IV and V) were found, suggesting that different SCCmec elements have been inserted into MSSA with the same genotype. All MRSA strains were resistant to tetracycline, but additional resistances to erythromycin, lincomycin, kanamycin and gentamicin were also found. All MRSA isolates were negative for the exfoliative toxin genes (eta and $e t b)$, PVL toxin genes $(l u k \mathrm{~F}$ and $l u k \mathrm{~S})$, toxic shock syndrome gene (tst-1), and the leukotoxin genes $\left(l u k \mathrm{E}, l u k \mathrm{D}, l u k \mathrm{M}, l u k \mathrm{~F}^{\prime}\right)$. (C) 2007 Elsevier B.V. All rights reserved.
\end{abstract}

Keywords: MRSA; Pig; Genotyping; Pig farms; Transmission; MLST; spa-Typing; PFGE

\footnotetext{
* Corresponding author. Tel.: +31 30 2533603; fax: +31 302533199.

E-mail address: e.duijkeren@vet.uu.nl (E. van Duijkeren).
} 


\section{Introduction}

In humans, methicillin-resistant Staphylococcus aureus (MRSA) are an important cause of hospitalacquired infections worldwide. MRSA is not confined to health care settings and during the last 10 years community-acquired MRSA (CA-MRSA) has been reported increasingly as a cause of infection or colonization in healthy individuals, often in the absence of recognizable risk factors. In recent years, increasing numbers of reports have documented the occurrence of MRSA in animals, especially in dogs, cats and horses (Weese et al., 2000; van Duijkeren et al., 2004; Rankin et al., 2005). As in humans, MRSA can colonize skin, nasal and oral mucosae in healthy animals, or cause infections, especially wound infections (Moodley et al., 2006). Recently, Armand-Lefevre et al. (2005) identified pig farming as a risk factor for increased nasal $S$. aureus carriage. In the period 2004-2005, MRSA was cultured from three Dutch patients who had direct or indirect contact with pigs: an infant of a pig farmer, a son of a veterinarian and a pig farmer (Voss et al., 2005). These investigators also found 6 MRSA carriers among a group of 26 pig farmers. In 2006, screening of 540 fattening pigs at 9 slaughterhouses all over The Netherlands showed that $39 \%$ of the pigs carried MRSA (de Neeling et al., 2007). Recently three other patients with infections caused by pig-associated MRSA were described (Huijsdens et al., 2006; Ekkelenkamp et al., 2006; Schneeberger et al., 2006). Interestingly, all of the MRSA isolated from the pigs and pig-associated human cases were nontypeable by PFGE using SmaI macrorestriction, and were of multilocus sequence type (MLST) ST398, indicating clonal spread. Recently, Wulf et al. (2006) reported that MRSA carriage was $4.6 \%$ among 152 Dutch veterinary students and veterinarians in contact with livestock. These findings have consequences for the Dutch search and destroy policy, which has been very effective: in 2005 , only $2 \%$ of the $S$. aureus isolates from Dutch hospitals were resistant to oxacillin (SWAB, 2006). In The Netherlands, contact with pigs is now recognized as a risk factor for MRSA carriage. To date, the reasons for the high prevalence of MRSA ST398 in Dutch finishing pigs are unknown. One possible explanation is that farrowing- and farrow-tofinish farms are also colonized and sell colonized pigs to the finishing farms.
The aims of the present study were (i) to determine the prevalence of MRSA in healthy pigs at different kinds of pig farms in order to identify possible sources of MRSA for finishing pigs; (ii) to examine if the usage of antimicrobial drugs increases the risk of finding MRSA-positive pigs on a farm; (iii) to analyze the porcine MRSA by pulsed field gel electrophoresis (PFGE), staphylococcal cassette chromosome mec (SCCmec) typing, multilocus sequence typing (MLST), spa-typing, the presence of genes encoding for toxins and susceptibility.

\section{Materials and methods}

\subsection{Survey on the farms}

In the period between August 2006 and November 2006, nasal swabs were collected from healthy pigs on 31 pig farms in The Netherlands: 12 farrowing farms, 11 finishing farms, 6 farrow-to-finish farms, 1 rearing farm and 1 centre for artificial insemination. All samples were convenience samples. Most farms $(n=25)$ belonged to the ambulatory clinic of the Veterinary Faculty and are located in Utrecht province. The other six farms are located in different provinces of The Netherlands. On each farm 10 randomly selected pigs were sampled and 1 nasal swab per pig, from both nares, was taken. On the centre for artificial insemination we sampled the boars, on the rearing farm the gilts, on the farrowing farms the weaned pigs, on the farrow-to-finish farms the finishers and on the finishing farms the finishers. Each farmer was asked if the batch of pigs we sampled had been treated with antimicrobial drugs, what kind of antimicrobial drugs and at what moment. Only group treatments and not individual treatments of pigs were registered. In addition a swab was taken from the farmers on a voluntary basis, from the throat and from both nares, with subjects' informed consent. One of the farms, where the farmer was carrier of MRSA, was sampled a second time, after the pigs had been treated with tetracycline in order to cure a respiratory disease.

In the second part of our study, we sampled pigs at six farms supplying pigs for the MRSA-positive farms, in order to investigate whether farms obtain MRSA through the purchase of colonized pigs. One MRSA-positive farm from the first part of our study 
was a closed farm, so no supplying farm could be sampled. If the MRSA-positive farm was a farrowing farm or a farrow-to-finish farm, samples were taken from 10 gilts on the supplying breeding farm; if the positive farm was a finishing farm, samples were taken from 10 weaned pigs on the supplying farrowing farm. The sampling was done as described above.

\subsection{Bacterial culturing}

The samples were incubated individually in MRSA broth, containing tryptic soy broth, $4 \%$ saline, $1 \%$ mannitol, phenol red $(16 \mu \mathrm{g} / \mathrm{ml})$, ceftizoxime $(5 \mu \mathrm{g} / \mathrm{ml})$ and aztreonam $(50 \mu \mathrm{g} / \mathrm{ml})$. The MRSA broth was incubated at $37^{\circ} \mathrm{C}$ for $48 \mathrm{~h}$ and then plated on sheep blood agar. The sheep blood agar was incubated at $37^{\circ} \mathrm{C}$ for $24 \mathrm{~h}$. Suspected colonies were identified as $S$. aureus using standard techniques: colony morphology, Gram staining, catalase and coagulase and by Pasteurex Staph-plus (Bio-Rad). The identity of the isolates was confirmed by a PCR specific for the nuc (thermonuclease) and mecA (PBP2a) genes. As internal amplification control a fragment of the 16S rRNA genes was amplified. The primer sets used were 5'-GCGATTGATGGTGATACGGTT and 5'-AGCCAAGCCTTGACGAACTAAAGC; 5'-GTTGTAGTTGTCGGGTTTGG and 5'-CTTCCACATACCATCTTCTTTAAC; 5'-AGGCCCGGGAACGTATTCAC and 5'-GAGGAAGGTGGGGATGACGT, respectively (de Neeling et al., 1998; Brakstad et al., 1992). Antimicrobial susceptibilities were determined by an agar diffusion method using Neo-sensitabs discs (Rosco, Denmark). The antimicrobials tested were tetracycline $(\mathrm{T})$, lincomycin $(\mathrm{L})$, erythromycin $(\mathrm{E})$, enrofloxacin (EN), trimethoprim/sulfamethoxazole (TS), gentamicin (G) and kanamycin (K). The breakpoints used were those recommended by the Dutch Committee on Guidelines for Susceptibility testing (CRG, 2000): for tetracycline, gentamicin, kanamycin and lincomycin zone diameters of $\geq 28 \mathrm{~mm}$ were regarded as susceptible and zone diameters of $<25$ were regarded as resistant; for enrofloxacin zone diameters of $\geq 26$ were regarded as susceptible and zone diameters $<23$ were regarded as resistant; for erythromycin zone diameters $\geq 27$ were regarded as susceptible and zone diameters $<23$ as resistant; for trimethoprim/sulfamethoxazole diameters of $\geq 28$ were regarded as susceptible en zone diameters of $<23$ as resistant.

\subsection{Genotyping of the MRSA}

The MRSA isolates were genotyped by PFGE using SmaI as restriction enzyme according to the Harmony protocol (Murchan et al., 2003), spa-typing (Harmsen et al., 2003) and multilocus sequence typing (MLST) (Enright et al., 2000). Typing of the SCCmec was performed by PCR (Ito et al., 2001, 2004; Okuma et al., 2002).

\subsection{Detection of toxin genes}

The detection of the exfoliative toxin genes eta and $e t b$, PVL toxin genes (lukF and lukS) (Lina et al., 1999), toxic shock syndrome gene (tst-1), and the leukotoxin genes (lukE and lukD) (Yamada et al., 2005) and $l u k \mathrm{M} / \mathrm{F}^{\prime}$ (Jarraud et al., 2002) was performed by PCR. The primers used for the detection of $t s t$ - 1 were ATT TTA CCC CTG TTC CCT TAT CAT $\mathrm{C}$ and TAG GTG GTT TTT CAG TAT TGT ATT $\mathrm{CA}$, for $e t a$ and $e t b$ CATTTGGTGCAGGTGTTGATTT and TCCACGGATTTTTATTTTATTTATTAC and ATATTATTTTTACACCCGCTCAA and TTCCCCAAAGTGTCTCCAAAAGTA respectively.

\section{Results}

On 7 of the 31 (23\%) investigated farms colonized pigs were found, including 3 finishing farms, 3 farrowing farms and 1 farrow-to-finish farm (Table 1). A total of 35 pigs (11\%) carried MRSA in their nares. The number of positive pigs ranged between 0 and 9 out of 10 pigs tested. Of the 10 farms on which antimicrobials were used as standard medication, 6 farms were MRSA positive. Of the 21 farms on which no standard medication with antimicrobials was used, only 1 farm was MRSA positive. On 2 of the 7 MRSApositive farms human MRSA carriers were found (3 colonized persons among 11 persons tested on 5 farms on which samples from humans were taken). On 18 of the 24 MRSA-negative farms, a total of 24 persons were tested and only 1 person was colonized with MRSA (on 6 MRSA-negative farms no samples from humans were taken). On one farm the farmer was colonized with MRSA, but the pigs were MRSA negative. After the pigs had been treated with oxytetracycline for acute respiratory disease, they were sampled a second time. 
Table 1

Data of the MRSA-positive farms

\begin{tabular}{|c|c|c|c|c|c|c|c|c|}
\hline Number & Kind of farm & $\begin{array}{l}\text { Supplier of } \\
\text { the pigs } \\
\text { for the } \\
\text { positive } \\
\text { farms }\end{array}$ & $\begin{array}{l}\text { Standard use of } \\
\text { antimicrobial } \\
\text { drugs/time }\end{array}$ & $\begin{array}{l}\text { Number of } \\
\text { positive pigs/ } \\
\text { number of } \\
\text { pigs tested }\end{array}$ & $\begin{array}{l}\text { Number of } \\
\text { human carriers/ } \\
\text { number of } \\
\text { persons tested }\end{array}$ & Spa-type & $\begin{array}{l}\text { SCCmec } \\
\text { type }\end{array}$ & $\begin{array}{l}\text { Resistance } \\
\text { pattern }^{\mathrm{a}}\end{array}$ \\
\hline 1 & Farrow-finish farm & & $\begin{array}{l}\text { Ampicillin doxycycline/ } \\
\text { at weaning }\end{array}$ & $9 / 10$ & $0 / 1$ & $\mathrm{t} 011$ & IV V & TGK and $\mathrm{T}$ \\
\hline 2 & Finishing farm & & $\begin{array}{l}\text { Trimethoprim- } \\
\text { sulphonamides/ } \\
\text { at } 11 \text { weeks }\end{array}$ & $2 / 10$ & $0 / 1$ & t899 & $\mathrm{V}$ & $\mathrm{T}$ \\
\hline 3 & Farrowing farm & $\begin{array}{l}\text { Closed } \\
\text { farm }\end{array}$ & $\begin{array}{l}\text { Colistin tulathromycin } \\
\text { amoxicillin/at weaning }\end{array}$ & $7 / 10$ & nt & $\mathrm{t} 567$ & $\mathrm{~V}$ & $\mathrm{~T}$ \\
\hline 4 & Farrowing farm & & Colistin/at weaning & $3 / 10$ & $0 / 3$ & $\mathrm{t} 108$ & V & $\mathrm{TE}$ \\
\hline 5 & Finishing farm & & $\begin{array}{l}\text { Tylosin doxycycline/ } \\
\text { therapeutic }\end{array}$ & $3 / 10$ & $1 / 2$ & $\mathrm{t} 108$ & $\mathrm{~V}$ & TEL \\
\hline 6 & Finishing farm & & Doxycycline/at weaning & $2 / 10$ & nt & $\mathrm{t} 011 \mathrm{t} 108$ & $\mathrm{~V}$ & TEL \\
\hline 7 & Farrowing farm & & Amoxicillin/at weaning & $9 / 10$ & $2 / 4$ & $\mathrm{t} 567$ & V & $\mathrm{T}$ and $\mathrm{TEL}$ \\
\hline A & Multiplier & 1 & Colistine & $0 / 10$ & $1 / 1$ & $\mathrm{t} 011$ & IV & TELGK \\
\hline B & Farrowing farm & 2 & Amoxicillin & $8 / 10$ & nt & t899 t1939 & $\mathrm{V}$ & TEL \\
\hline $\mathrm{C}$ & Multiplier & 4 & $\begin{array}{l}\text { Trimethoprim/ } \\
\text { sulfonamides }\end{array}$ & $2 / 10$ & $1 / 1$ & $\mathrm{t} 108$ & $\mathrm{~V}$ & $\mathrm{TE}$ \\
\hline $\mathrm{D}$ & Farrowing & 5 & None & $1 / 10$ & $1 / 3$ & $\mathrm{t} 108$ & $\mathrm{~V}, \mathrm{IV}$ & TEL \\
\hline $\mathrm{E}$ & Farrowing farm & 6 & Tetracycline & $8 / 10$ & $1 / 1$ & $\mathrm{t} 108$ & V & TEL \\
\hline $\mathrm{F}$ & Multiplier & 7 & Tetracycline amoxicillin & $4 / 10$ & $4 / 5$ & $\mathrm{t} 567$ & $\mathrm{~V}$ & $\mathrm{~T}$ and $\mathrm{TEL}$ \\
\hline
\end{tabular}

Farm numbers 1-7 are the MRSA-positive farms investigated in the first screening of 31 farms. Farms A, B, C, D, E, F are the farms supplying the pigs for farms $1,2,4,5,6$ and 7 . Farm 3 is a closed farm

a $\mathrm{T}=$ tetracycline, $\mathrm{E}=$ erythromycin, $\mathrm{L}=$ lincomycin, $\mathrm{G}=$ gentamicin, $\mathrm{K}=$ kanamycin, nt $=$ not tested.

The result of this second sampling was that 8 out of 10 pigs were MRSA positive.

On five of the six farms supplying pigs for the seven MRSA-positive farms the pigs were also MRSA positive. On 5 supplying farms human MRSA carriers were found ( 8 colonized persons among 11 persons tested). On the farm where all pigs were MRSA negative, the only person tested was MRSA positive. On one farm with MRSA-positive pigs, no human samples were taken (see Table 1). In total, colonized personnel was found on 8 out of 13 MRSA-positive farms investigated and only 1 of the 18 MRSAnegative farms investigated.

The MRSA strains had resistance patterns T, TE, TEL, TKG and TELKG. On three farms MRSA with two different resistance patterns ( $\mathrm{T}$ and TGK; $\mathrm{T}$ and TEL) were found. All MRSA isolates were negative for the PVL leucocidin toxin genes ( $l u k \mathrm{~S}$ and $l u k \mathrm{~F})$, for the toxic shock syndrome gene (tst-1), the leukotoxin genes ( $l u k \mathrm{E}, l u k \mathrm{D}, l u k \mathrm{M}$ and $l u k \mathrm{~F}$ ') and for exfoliative toxins A and B. All isolates were untypable by PFGE using SmaI digestion, and had ST398. Five related spa-types were found: t011, t108, t567, t899 and $\mathrm{t} 1939$ (Table 2). On the farms, which were epidemiologically related, the same spa-types were found. The spa-types found in the pigs and the farmer on a farm was also identical. Two SCCmec types were found, SCCmec type IV and V. SCCmec type V predominated (Table 1). Remarkably, different SCCmec types (IV and $\mathrm{V}$ ) were found among the MRSA isolates from the pigs on one farm in isolates with the same spa-type t011, but with different resistance patterns (TKG and T). On another farm the MRSA isolates cultured from the pigs had an SCCmec type differing from the SCCmec type of the isolates from the farmer, although the spa-types were identical.

\section{Discussion}

An important finding of our study was the occurrence of MRSA on different kinds of pig farms 
Table 2

Spa-types and repeat succession of the MRSA isolates found in the present study

\begin{tabular}{lll}
\hline Spa type & Tandem repeats & Number of farms with this type \\
\hline t108 & $008-16----02-25----24-25$ & 6 \\
t011 & $008-16----02-25-34-24-25$ & 3 \\
t567 & $008------02-25----24-25$ & 3 \\
t899 & $007-16-23-02----34------$ & 2 \\
t1939 & $007----23-02----34------$ & 1 \\
\hline
\end{tabular}

and their supplying farms. The spa-types of the MRSA isolates found on the farms and their respective supplying farms were identical. Porcine MRSA isolates with the rare spa-type t899, which has not been reported before in pigs, was found on a finishing farm and the farrowing farm supplying the piglets for the finishing farm. Together, these data indicate that finishing farms and farrowing farms may be colonized by MRSA through the purchase of colonized pigs from other farms. This knowledge is essential for choosing the right strategy for future programs aimed at controlling the spread of MRSA in pigs. However, importing colonized pigs is perhaps not the only way of propagation of MRSA, as one closed farm was also MRSA positive. MRSA may also be spread repeatedly between pigs on farms without an all-in all-out system; between colonized personnel/veterinarians and the pigs or between the contaminated environment and the pigs and therefore continual introduction is probably not necessary.

Another important finding of our study was that the use of standard antimicrobials for the pigs seems to be a risk factor for finding MRSA-positive pigs on a farm. Pig farms on which the pigs were treated with antimicrobials as group medication had a higher risk of being MRSA positive, whereas farms on which antimicrobials were used restrictively had a much lower chance of being MRSA positive. The MRSA isolates were resistant to beta-lactam antibiotics, tetracycline, aminoglycosides, lincosamides and macrolides and therefore the use of these antimicrobials may select for the pig-associated MRSA. Tetracyclines are extensively used as group medication in the Netherlands. Remarkably, all MRSA isolates were susceptible to trimethoprim/sulfonamides, although these drugs are also used commonly in pigs. On one farm the pigs were MRSA positive after they had been treated with oxytetracycline. The farmer, however, was MRSA positive during the first screening. Possibly the pigs were already colonized with MRSA before the treatment, but the level of colonization was below the limit of our detection method. Another cause might be that the respiratory disease predisposed the pigs to colonization.

The prevalence of MRSA-positive pig farms (23\%) in our study was lower than the prevalence reported by de Neeling et al. (2007) (81\%). An explanation for this might be that we included a large number of farms belonging to the ambulatory clinic of the Veterinary Faculty. On these farms the use of antimicrobial drugs is generally more restricted compared to other farms. Another reason might be that we sampled pigs on the farms, whereas in the other study (de Neeling et al., 2007) the pigs were sampled at slaughterhouses. The higher prevalence in the slaughterhouses may have been caused by cross contamination in the lairages, because the percentage of MRSA-positive pigs was significantly different between slaughterhouses (de Neeling et al., 2007). A third explanation might be differences between the sensitivity of the culture techniques used.

Colonized personnel was found more often at the MRSA-positive farms investigated indicating that farmers/personnel on MRSA-positive farms have a greater chance of being colonized with MRSA than farmers/personnel on MRSA-negative farms.

All MRSA isolates had MLST 398 and 5 different, but closely related spa-types were found suggesting clonal spread. However, on two farms MRSA isolates with the same spa-type but with different SCCmec types were found. This suggests that different SCCmec elements have been inserted into MSSA with the same genotype. The MRSA isolated from the pigs and pigassociated human cases are non-typeable by PFGE using SmaI macrorestriction, because they posses a restriction modification enzyme which methylates the 
SmaI-recognition sequence (Bens et al., 2006). We did not find Panton Valentine leucocidin toxin genes, the toxic shock syndrome gene, leukotoxin genes or exfoliative toxins $\mathrm{A}$ and $\mathrm{B}$ in the pig-associated MRSA isolates. However this MRSA could acquire one or more of these toxin genes because these genes can be present on mobile elements like plasmids and bacteriophages. If the pig-associated MRSA acquires one or more toxin genes this could increase its pathogenicity.

In conclusion, $23 \%$ of the pig farms were MRSA positive and five out of six farms supplying pigs for the positive farms were also MRSA positive, indicating transmission within the production chain. The use of antimicrobial drugs as group medication was associated with finding MRSA colonized pigs on a farm.

\section{References}

Armand-Lefevre, L., Ruimy, R., Andremont, A., 2005. Clonal comparison of Staphylococcus aureus isolates from healthy pig farmers, human controls, and pigs. Emerg. Infect. Dis. 11, 711-714.

Bens, C.C., Voss, A., Klaassen, C.H., 2006. Presence of a novel DNA methylation enzyme in methicillin-resistant Staphylococcus aureus isolates associated with pig farming leads to uninterpretable results in standard pulsed-field gel electrophoresis analysis. J. Clin. Microbiol. 44, 1875-1876.

Brakstad, O.G., Aasbakk, K., Maeland, J.A., 1992. Detection of Staphylococcus aureus by polymerase chain reaction amplification of the nuc gene. J. Clin. Microbiol. 30, 1654-1660.

CRG, 2000. Commissie Richtlijnen Gevoeligheidsbepalingen, Interpretatie van gevoeligheidsonderzoek en gevoeligheidscriteria voor antibacteriële middelen in Nederland. Ned. Tijdschr. Med. Microbiol. 8, 79-81.

de Neeling, A.J., van Leeuwen, W.J., Schouls, L.M., Schot, C.S., van Veen-Rutgers, A., Beunders, A.J., Buiting, A.G., Hol, C., Ligtvoet, E.E., Petit, P.L., Sabbe, L.J., van Griethuysen, A.J., van Embden, J.D., 1998. Resistance of staphylococci in The Netherlands: surveillance by an electronic network during 1989-1995. J. Antimicrob. Chemother. 41, 93-101.

de Neeling, A.J., van den Broek, M.J.M., Spalburg, E.C., van Santen-Verheuvel, M.G., Dam-Deisz, W.D.C., Boshuizen, H.C., van de Giessen, A.W., van Duijkeren, E., Huijsdens, X.W., 2007. High prevalence of methicillin resistant Staphylococcus aureus in pigs. Vet. Microbiol. 122, 366-372.

Ekkelenkamp, M.B., Sekkat, A., Carpaij, N., Troelstra, A., Bonten, M.J.M., 2006. Endocarditis door meticilline resistente Staphylococcus aureus afkomstig van varkens. Ned. Tijdschr. Geneeskd. 150, 2442-2447.

Enright, M.C., Day, N.P., Davies, C.E., Peacock, S.J., Spratt, B.G., 2000. Multilocus sequence typing for characterization of methi- cillin-resistant and methicillin-susceptible clones of Staphylococcus aureus. J. Clin. Microbiol. 38, 1008-1015.

Harmsen, D., Claus, H., Witte, W., Rothganger, J., Claus, H., Turnwald, D., Vogel, U., 2003. Typing of methicillin-resistant Staphylococcus aureus in a university hospital setting by using novel software for spa repeat determination and database management. J. Clin. Microbiol. 41, 5442-5448.

Huijsdens, X.W., van Dijke, B.J., Spalburg, E., van Santen-Verheuvel, M.G., Heck, M.E.O.C., Pluister, G.N., Voss, A., Wannet, W.J.B., de Neeling, A.J., 2006. Community-acquired MRSA and pig-farming. Ann. Clin. Microbiol. Antimicrob. 5, 26.

Ito, T., Katayama, Y., Asada, K., Mori, N., Tsutsumimoto, K., Tiensasitorn, C., Hiramatsu, K., 2001. Structural comparison of three types of staphylococcal cassette chromosome mec integrated in the chromosome in methicillin-resistant Staphylococcus aureus. Antimicrob. Agents Chemother. 45, 13231336.

Ito, T., Ma, X.X., Takeuchi, F., Okuma, K., Yuzawa, H., Hiramatsu, K., 2004. Novel type V staphylococcal cassette chromosome mec driven by a novel cassette chromosome recombinase, $\operatorname{ccrC}$. Antimicrob. Agents Chemother. 48, 2637-2651.

Jarraud, S., Mougel, C., Thioulouse, J., Lina, G., Meugnier, H., Forey, F., Nesme, X., Etienne, J., Vandenesch, F., 2002. Relationships between Staphylococcus aureus genetic background, virulence factors, agr groups (alleles), and human disease. Infect. Immun. 70, 631-641.

Lina, G., Piemont, Y., Godail-Gamot, F., Bes, M., Peter, M.O., Gauduchon, V., Vandenesch, F., Etienne, J., 1999. Involvement of Panton-Valentine leukocidin-producing Staphylococcus aureus in primary skin infections and pneumonia. Clin. Infect. Dis. 29, 1128-1132.

Moodley, A., Stegger, M., Bagcigil, A.F., Baptiste, K.E., Loeffler, A., Lloyd, D.H., Williams, N.J., Leonard, N., Abbott, Y., Skov, R., Guardabassi, L., 2006. Spa typing of methicillin-resistant Staphylococcus aureus isolated from domestic animals and veterinary staff in the UK and Ireland. J. Antimicrob. Chemother. 58, 1118-1123.

Murchan, S., Kaufmann, M.E., Deplano, A., de Ryck, R., Struelens, M., Zinn, C.E., Fussing, V., Salmenlinna, S., Vuopio-Varkila, J., El Solh, N., Cuny, C., Witte, W., Tassios, P.T., Legakis, N., van Leeuwen, W., van Belkum, A., Vindel, A., Laconcha, I., Garaizar, J., Haeggman, S., Olsson-Liljequist, B., Ransjo, U., Coombes, G., Cookson, B., 2003. Harmonization of pulsed-field gel electrophoresis protocols for epidemiological typing of strains of methicillin-resistant Staphylococcus aureus: a single approach developed by consensus in 10 European laboratories and its application for tracing the spread of related strains. J. Clin. Microbiol. 41, 1574-1585.

Okuma, K., Iwakawa, K., Turnidge, J.D., Grubb, W.B., Bell, J.M., O’Brien, F.G., Coombs, G.W., Pearman, J.W., Tenover, F.C., Kapi, M., Tiensasitorn, C., Ito, T., Hiramatsu, K., 2002. Dissemination of new methicillin-resistant Staphylococcus aureus clones in the community. J. Clin. Microbiol. 40, 4289-4294.

Rankin, S., Roberts, S., O'Shea, K., Maloney, D., Lorenzo, M., Benson, C.E., 2005. Panton-Valentine leukocidin (PVL) toxin positive MRSA strains isolated from companion animals. Vet. Microbiol. 108, 145-148. 
Schneeberger, P., Gend, W., van Smiseth, O.A., 2006. Varken bijt boer. Med. Contact 61, 969., http://www.rivm.nl/gezondheid/ infectieziekten/meer_informatie_MRSA_bij_varkens.jsp.

SWAB, 2006. NethMap 2006 consumption of antimicrobial agents and antimicrobial resistance among medically important bacteria in the Netherlands. http://www.swab.nl.

van Duijkeren, E., Box, A.T.A., Heck, M.E.O.C., Wannet, W.J.B., Fluit, A.C., 2004. Methicillin-resistant staphylococci isolated from animals. Vet. Microbiol. 103, 91-97.

Voss, A., Loeffen, F., Bakker, J., Klaassen, C., Wulf, M., 2005. Methicillin-resistant Staphylococcus aureus in pig farming. Emerg. Infect. Dis. 11, 1965-1966.

Weese, J.S., Archambault, M., Willey, B.M., Dick, H., Hearn, P., Kreiswirth, B.N., Said- Salim, B., McGeer, A., Likhoshvay, Y.,
Prescott, J.F., Low, D.E., 2000. Methicillin-resistant Staphylococcus aureus in horses and horse personnel. 2000-2002. Emerg. Infect. Dis. 11, 430-435.

Wulf, M., van Nes, A., Eikelenboom-Boskamp, A., de Vries, J., Melchers, W., Klaassen, C., Voss, A., 2006. Methicillinresistant Staphylococcus aureus in veterinary doctors and students, the Netherlands. Emerg. Infect. Dis 12, 19391941.

Yamada, T., Tochimaru, N., Nakasuji, S., Hata, E., Kobayashi, H., Eguchi, M., Kaneko, J., Kamio, Y., Kaidoh, T., Takeuchi, S., 2005. Leukotoxin family genes in Staphylococcus aureus isolated from domestic animals and prevalence of $l u k \mathrm{M}-l u k \mathrm{~F}-\mathrm{PV}$ genes by bacteriophages in bovine isolates. Vet. Microbiol. 30 (110), 97-103. 